questions such as: why should predictions from simpler theories be generally more reliable?; why should analogical arguments from theory to theory work as well as they do? I believe van Fraassen's comparatively cavalier dismissal of such problems of epistemology, induction and confirmation can be traced to his exclusively deductive (and sometimes statistical) construal of the formal character of theories. But theories are not treated in scientific practice as axiomatized entities; they have much fuzzier edges than that, and reliably support inferences that are not just deductive or formally statistical.

Such limitations apart, however, this book for the first time makes a clear statement of what is involved in scientific realism, and it will become the classic current argument against that philosophical position. It successfully debunks recent exaggerated attention to the concept of "explanation", and replaces it with a healthy concern with truth and empirical adequacy that does not give any hostages to relativism. Tactically, its relative conservatism about the general philosophical implications of philosophy of science will make it all the more influential among realist philosophers. Scientists, however, may well be ready for more radical investigation of the effects of changing scientific theories on our commonsense presuppositions, and particularly on our views of logic, natural language and scientific inference.

Mary Hesse is Professor of Philosophy of Science, University of Cambridge.

\title{
Archaeological jargon explained
}

\section{A. F. Harding}

A Dictionary of Terms and Techniques in Archaeology. By Sara Champion. Pp. 144. (Phaidon/Facts on File: 1980.) Hbk £6.95, \$15.95; pbk £4.95.

THE Introduction to this little volume tells us that the book "is not a general dictionary of archaeology: names of cultures and artefacts have been deliberately omitted". Instead, it "has been compiled with the aim of introducing to non-professional archaeologists the terms and techniques used in modern archaeology"'. The author disclaims personal expertise in most of the techniques described, and has generally provided brief (typically 30 to 300 word) entries with a reference to a standard work on the subject.

Despite its limited brief, professionals and students, as well as interested amateurs, will find much of practical use in this book, especially for checking up on those jargon terms one so frequently hears but secretly wonders about. The Dictionary contains only about 330 entries, many of them illustrated, so the scope is necessarily selective: most space is devoted to modern archaeological theory, scientific techniques in archaeology, archaeological techniques per se, terms from related disciplines and a certain number of technological terms - especially those relating to potting and metalworking. Stone and stone-working, to take a single example, are barely touched upon.

Each reader will undoubtedly find his own lacunae, and it is a pity that the author was not able to roam more freely. Yet the book is well-produced and within its selfimposed limits can be recommended.

A. F. Harding is a Lecturer in Archaeology at the University of Durham.

\section{The biology of history}

\section{Hugh Thomas}

The Human Condition. By W. H. McNeill. Pp.75. (Princeton University Press: 1980.) $£ 4.75, \$ 11.25$.

UNIVERSAL histories are becoming alarmingly fashionable. This is understandable for three reasons. First, alt hough we are a long way still from anything like a world state we are quite close to an interdependent world society. The slightest hiccup in southern Asia affects northern Europe. Oil, especially, is the great internationalizing force, causing all responsible people to remember statistics of production in countries whose very names were unknown to them ten years ago. Second, the concentration of such enormous power in the hands of two superpowers is, also, a development which has never occurred before in human history: until 1945, power was always far more widely dispersed. The third explanation is that the apparent long-term shortages in raw materials have persuaded human beings to reflect seriously over the springs of their predicament in a new way. There is no doubt but that this is a benefit. National revival is unilaterally possible (such as occurred in France in 1958) but it is unlikely to occur save in the climate of international prosperity.

W. H. McNeill is no newcomer to the grand approach. His Rise of the West (Chicago University Press, 1963) is rightly regarded as one of the best, probably the best, of the conventional outline general histories. His Plagues and Peoples (Blackwell, 1977) was an extremely interesting introduction to the role of disease in history. The Human Condition is more modest, being merely two (long) lectures given at Clark University. Or at first sight modest, because, after all, there is a sense in which any book with this title which seeks adequately to cope with such a subject-matter in 75 pages is magnificently ambitious.

The themes of Professor McNeill's essay (for such it is) derive from his earlier study of disease. The main concept is what he calls "parasitism", divided in its challenge to human beings into "macroparasites" and "microparasites". Microparasitism refers to the "metabolic activities of minute organisms" which compete with human beings for food: by getting there first, microparasites can forestall human efforts to capture energy from food. Macroparasitism is any "exploitative relations among groups and classes of human beings", such as when one man or group of men - armed raiders, tax collectors, rent collectors - seize goods or compel services from other groups.

This rather forbidding frame gives Professor McNeill a justification for what turns out to be an extremely lively and wellwritten short world history, with the use of little jargon other than that I have already quoted. The frame enables Professor McNeill to make some interesting and novel points: for example, he attributes the advance of our remotest ancestors to the "apex of the food chain" to the acquisition of language and to the superior coordination of human behaviour that language allowed. The next landmark was the use of clothes to "maintain a tropical microenvironment" next to the almost hairless skin we all inherit. A bearskin on the back enabled us to live in a cold climate. Agriculture, though a definite benefit, Professor McNeill somewhat grudgingly confirms, brought microparasites as well as harvests. Irrigation brought mosquitoes. The "first recorded conqueror" Sargon of Akkad (c.2250 BC) was the first macroparasite on an imperial scale. Civil servants were the consequence - a problem with which we are still wrestling. In the sixteenth century, a fundamental change occurred, worthy of greater attention than Professor McNeill gives it businessmen succeeded in establishing real autonomy from their political superiors, with even the mightiest European rulers depending on traders and bankers to 